\title{
A Finite Element Model for Wave Propagation in an Inhomogeneous Material Including Experimental Validation
}

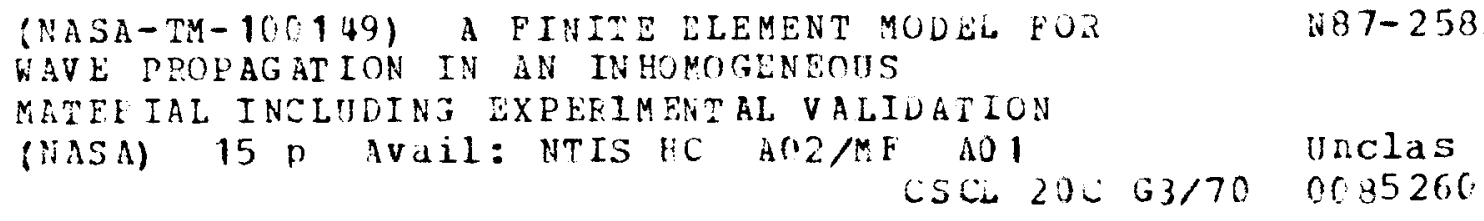

Kenneth J. Baumeister and Milo D. Dahl

Lewis Research Center

Cleveland, Ohio

Prepared for the

11 th Aeroacoustics Conference sponsored by the American Institute of Aeronautics and Astronautics Sunnyvale, California, October 19-21, 1987 
A FINITE ELEMENT MODEL FOR WAVE PROPAGATION IN AN INHOMOGENEOUS

MATERIAL INCLUDING EXPERIMENTAL VALIDATION

Kenneth J. Baumeister and Milo D. Dahl

National Aeronatics and Space Administration

Lewis Research Center

Cleveland, Ohio 44135

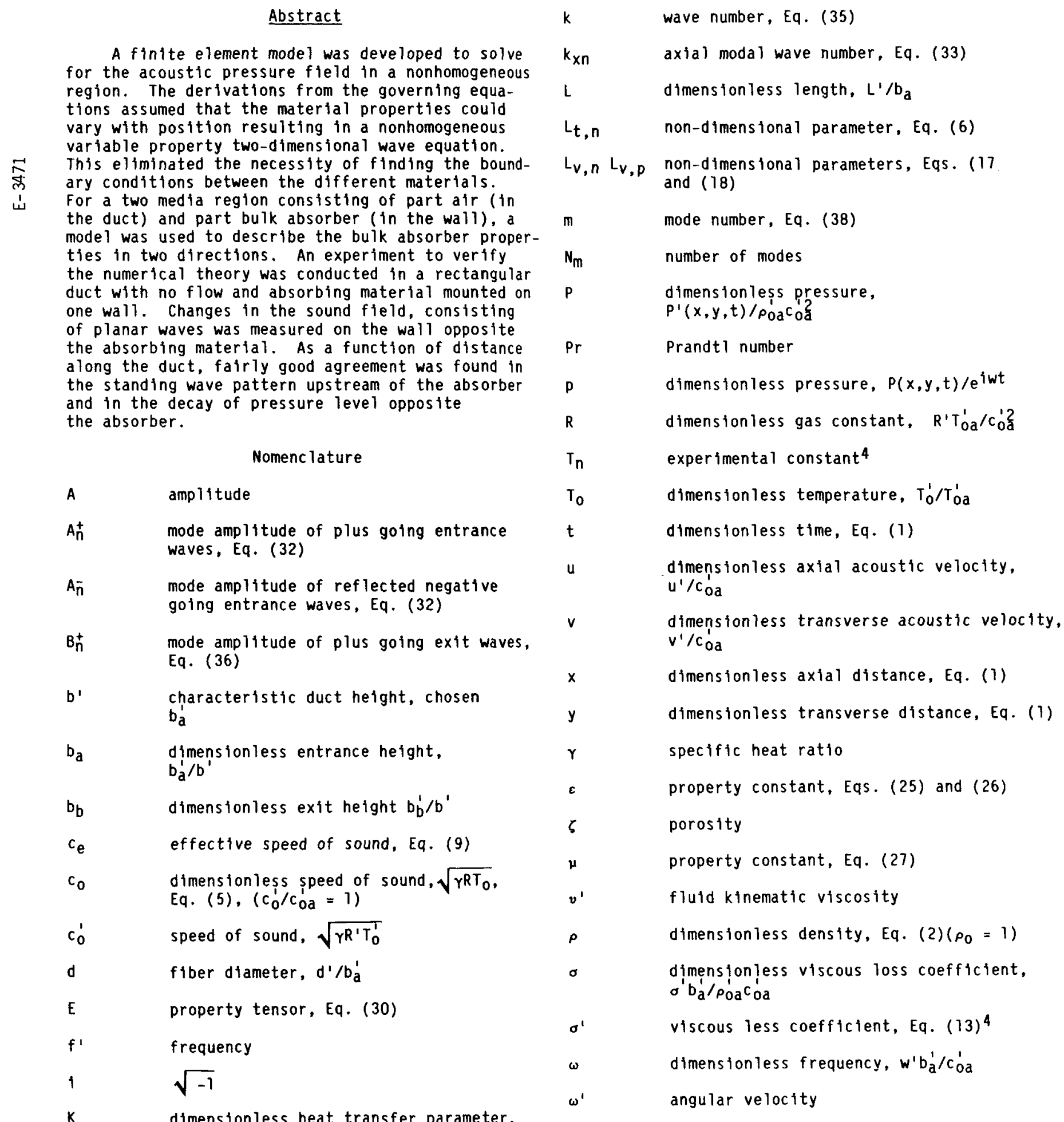

$\mathrm{X}^{\prime} \mathrm{ba} / \mathrm{Poa}_{\mathrm{O}} \mathrm{Oa}$, Eq. $(20)^{4}$ 


\section{Subscripts}

a inlet duct condition

b exit duct condition

$1 \quad 1^{\text {th }}$ nodal point

o ambient conditions

$x, y \quad$ scalor vector components

Superscripts

' dimensional quantity

approximate finite element solution

\section{Introduction}

The relatively high fuel economy available from propeller-driven alrcraft has renewed interest in high speed, highly loaded, multiple blade turboprop propulsion systems. The acoustic testing ${ }^{1}$ of a scaled multiple blade propeller has been carried out in the 9- by 15-Ft Low Speed Wind Tunnel at NASA Lewis Research Center. Under simulated flight conditions in the wind tunnel, it is desirable to measure both acoustic amplitude and directivity to help fully characterize the propeller noise source. This is not possible if reflections from the wind tunnel walls are interfering with the direct sound. Consequently, the NASA Lewis 9- by 15-Ft Low Speed Wind Tunnel was acoustically lined to reduce tunnel reverberations.

At the same time as measurements were made in the wind tunnel, analys is was done to provide data on how the measurements were affected by various acoustic parameters. In Ref. 2, Baumeister and Eversman used finite element theory to calculate the acoustic field of a propeller in a soft walled wind tunnel and compared these results to the radiation patterns of the same propeller in free space. They found that complicated pressure flelds exist in a lined wind tunnel and that only over limited portions of the tunnel can measurements approximating the free field be obtained.

The hard Helmholtz resonator cavity and a bulk ftbrous absorber are the most common materlals employed to attenuate sound. A bulk absorber called Kevlar was chosen as the wall absorbing material in the 9- by 15- Ft NASA Lewis Wind Tunnel. Design and construction of the wall liner was performed at NASA Lewis and is documented in Ref. 3 . In contrast to a locally reacting liner, such as the Heimholtz resonator shown in Fig. 1(a), the bulk extended reaction liner permits wave propagation in the axial direction, as shown in Fig. 1(b).

In Ref. 2, the absorbing characteristics of the wind tunnel walls were modeled by applying the classical admittance boundary conditions at the tunnel walls. Consequently, wave propagation in the axial direction in the bulk liner was not considered. The present investigation will use finite element theory to develop a model to conveniently handle wave propagation in bulk material as well as in any inhomogeneous medium. The absorbing characteristics of the bulk material used in this model rely on the theoretical development presented by Hersh. ${ }^{4}$
First, the geometric model and the appropriate governing equations and boundary conditions will be presented. Next, the finite element procedure for solving the problem will be discussed. Then, a numerical solution and an analytical solution to a test problem will be compared. Finally, the results of a validation experiment will be discussed and compared to theory.

\section{Geometrical Model}

In the finite element model of a tunnel with bulk absorbing materlals along the wall, the present paper will focus on the interaction of propagating duct modes with the wall lining as shown in Fig. 2. In the uniform, infinitely long entrance and exit regions with perfectly hard wall, the exact solution of the governing differential equations can be easily written in terms of the duct modes. In the central region which includes both the duct and the fibrous absorbing region, the finite element analysis is employed to determine the ressure fleld in this nonuniform region. Pressure waves propagating down the duct are either reflected, transmitted or absorbed by the nonuniform segment of the duct.

Pressure mode reflection at the inlet to the absorbing region and transmission at the outlet of the absorbing region are modeled by matching the finite element solution in the interfor of the central region to the known analytical eigen function expansions in the uniform inlet and outlet ducts. This permits a multimodal representation accounting for reflection and mode conversion by the nonuniform absorbing section. This approach has been found to accurately model reflection and transmission coefficients. 5

\section{Governing Equations}

The governing equations are the state, continuity, and momentum inearized gas dynamics equations in the absence of a mean flow. In the fibrous material, the Hersh form ${ }^{4}$ of the governing equations will be employed. By treating the bulk material as a momentum and thermal sink, Hersh modifled the conventional linearlzed gas equation such that new complex propagation constants would account for acoustic energy absorption in the material. The development was semi-empirical since an adjustable constant was employed; however, the dimenstonal parameters developed appear to accurately follow experimental trends. Different sets of constants were determined for the fibers oriented perpendicular to or parallel to the incident sound particle velocity field. Consequently, some properties in the following equation will be subscripted with either $x$ or $y$ to indicate anisotropic behavior.

The Hersh mode $1^{4}$ was developed for acoustic propagation in one dimension. Herein, the model will be extended to two-dimensional propagation.

The differential equations used herein are put in non-dimensional form form using

$$
\begin{aligned}
& t=t^{\prime} \frac{c^{\prime}}{b_{a}^{\prime}} \quad x=\frac{x^{\prime}}{b_{a}^{\prime}} \quad y=\frac{y^{\prime}}{b_{a}^{\prime}} \\
& \rho=\frac{\rho^{\prime}}{\rho_{o a}^{\prime}} T=\frac{T^{\prime}}{T_{o a}^{\prime}} \quad P=\frac{P^{\prime}}{\rho_{o a}^{\prime} c^{\prime 2}}
\end{aligned}
$$


In the foregoing equations, the prime, ', is used to denote a dimensional quantity and the umprimed defines a dimensionless quantity. This convention will be used throughout this paper. These and all other symbols used in the report are defined in the Nomenc lature. Generally, conventional acoustic notation will be used so that the significance of most symbols are readily recognized.

\section{Equation of State}

The equation relating acoustic pressure and density used in the bulk absorber was derived in Ref. 4 using a one-dimensional model for the heat transfer between the sound field and the fibers. The heat transfer equation was used to determine a relationship between temperature and density perturbations in the fluid surrounding the fibers. This relationship and the linearized perfect gas law yielded the following relationship between pressure and density perturbations which are assumed to hold in two-dimensions:

$$
P(x, y, t)=R T_{0}\left[\frac{\left(\frac{K}{\rho_{0} \omega}\right)+i \gamma}{\left(\frac{K}{\rho_{0} \omega}\right)+i}\right] \rho(x, y, t)
$$

where the dimensionless frequency $\omega$ is defined as

$$
\omega=\frac{\omega^{\prime} b^{\prime}}{C_{\text {oa }}^{\prime}}
$$

The parameters $x$ is defined in Ref. 4 as

$$
\frac{K}{\rho_{0} w}=\frac{4 \gamma}{P_{r}}\left(\frac{v^{\prime}}{w^{\prime} d^{\prime 2}}\right)\left(\frac{1-\zeta}{\zeta}\right) \frac{1}{\frac{L_{t, n}}{d}}
$$

\{Eq. (21) Ref. 4\}

where

$$
\frac{L_{t, n}}{d}=\frac{T_{n}}{\left.5.4 \sqrt{1-\zeta\left[1+3.94(1-\zeta)^{3}\right.}\right]}
$$

In Eqs. ( 3 ) and (5), the symbol $K$ denotes a heat transfer parameter that is connected to the properties of the fluid medlum and the fiber matertal ( $\mathrm{Eq} .(20)) .4$

The two limiting cases of the state equation correspond to the isothermal and adlabatic relationships between the pressure $P$ and density $p$. At very low frequencles wherein $K / \rho_{0} \omega \gg 1$,

$$
P(x, y, t) \simeq R T_{O P}(x, y, t)
$$

which represents the isothermal relationship. At very $h i g h$ frequencles, wherein $K / \rho_{0} \omega \ll 1$,

$$
P(x, y, t) \simeq \gamma R T_{O} \rho(x, y, t)
$$

the adiabatic relationship is recovered. Further interpretation of Eq. (3) can be found in Ref. 4.

For simplicity, in the general case as given by Eq. (3), the effective speed of sound is now defined as

$$
c_{e}^{2}=\frac{\partial P}{\partial \rho}=R T_{0}\left[\frac{\left(\frac{K}{\rho_{0} \omega}\right)+i \gamma}{\left(\frac{K}{\rho_{0} \omega}\right)+i}\right]=\frac{c^{2}}{\gamma}\left[\frac{\left(\frac{K}{\rho_{0} \omega}\right)+i \gamma}{\left(-\frac{K}{\rho_{0} \omega}\right)+i}\right]
$$

Thus, the equation of state can now be written as

$$
P(x, y, t)=c_{e}^{2} \rho(x, y, t)
$$

\section{Continuity Equation}

The continulty equation in the bulk material can be written as

$$
\frac{\partial \rho(x, y)}{\partial t}+\frac{\rho_{0}}{\zeta} \frac{\partial u}{\partial x}+\frac{\rho_{0}}{\zeta} \frac{\partial v}{\partial y}=0
$$

where $\zeta$ represents the porosity of the medium. In the main inlet channel without fibers, $\zeta$ has a value of unity. In the fibrous material $\zeta$ is a fraction less than one whose value depends on the packing density of the material. In this continuity equation, the particle mass flow is conserved where the air (or any gas) density $\rho_{0}$ is constant in the medium and in the air gaps surrounding the fibers.

Substituting the equation of state, Eq. (10), into Eq. (11) and taking the derivative with respect to time yields

$$
\frac{\partial^{2} u}{\partial t \partial x}+\frac{\partial^{2} v}{\partial t \partial y}+\frac{\zeta}{\rho_{0} c_{e}^{2}} \frac{\partial^{2} p}{\partial t^{2}}=0
$$

Momentum Equations

The $x$ and $y$ momentum equation $c$ an be written as

$$
\begin{gathered}
\frac{\rho_{0}}{\zeta} \frac{\partial u}{\partial t}=-\frac{\partial P}{\partial x}-\sigma_{x} \frac{u}{\zeta} \\
\frac{\rho_{0}}{\zeta} \frac{\partial v}{\partial t}=\frac{-\partial P}{\partial y}-\sigma_{y} \frac{v}{\zeta}
\end{gathered}
$$

Here, the momentum equations have been empirically modified with a viscous loss coefficient o (Eq. 13, Ref. 4) resulting from skin friction, shear stresses and drag.

$$
\begin{aligned}
& \frac{\sigma_{x}}{\rho \omega}=-\frac{4 v^{\prime}}{\omega^{\prime} d^{\prime 2}}(1-\zeta) \frac{v_{n}}{\frac{L v, n}{d}} \\
& \frac{\sigma_{y}}{\rho \omega}=\frac{4 v^{\prime}}{\omega^{\prime} d^{\prime}}(1-\zeta) \frac{v_{p}}{\frac{L v_{l} p}{d}}
\end{aligned}
$$

where $v_{n}$ and $v_{p}$ are arbitrary constants based on measurements and the parameters $L_{v, n}$ and $L_{v, p}$ are those used in Ref. 4

$$
\frac{L_{v, n}}{d}=\frac{1}{16 \sqrt{1-\zeta\left[1+14.75(1-\zeta)^{3}\right]}}
$$

and

$$
\frac{L_{v, D}}{d}=\frac{1}{3.94(1-\zeta)^{0.413\left[1+27(1-\zeta)^{3}\right]}}
$$


This is an extension of the one-dimensional model used in Ref. 4 which used a viscous loss coefficient corresponding to

$$
\sigma=\sigma_{x}+\sigma_{y}\{\text { Eq. 13, Ref. } 4\}
$$

The $x$ momentum Eq. (13) can be rewritten in the form

$$
\frac{P_{0}}{\zeta} \quad \frac{\partial u}{\partial t}=-\frac{\partial P}{\partial x}-\frac{\sigma_{x}}{\zeta t_{\omega}} \frac{\partial u}{\partial t}
$$

where $u$ has been assumed to be a harmonic function of time. Thus,

$$
\frac{\partial u}{\partial t}=\frac{-1}{\left(\frac{\rho_{0}}{\zeta}+\frac{\sigma_{x}}{\zeta \omega_{\omega}}\right)} \frac{\partial P}{\partial x}
$$

Taking the $x$ derivative of Eq. (21) yields

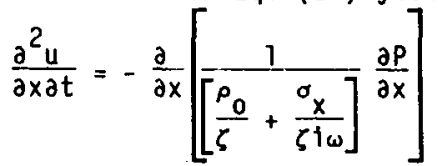

\section{Wave Equation}

Substituting Eq. (22) and the similar y form of the momentum equation into the modified form of the continuity Eq. (12) yields

$\frac{\partial}{\partial x}\left[\frac{1}{\left(\frac{\rho_{0}}{\zeta}+\frac{\sigma_{x}}{\zeta^{i} \omega}\right)} \frac{\partial P}{\partial x}\right]+\frac{\partial}{\partial y}\left[\frac{1}{\left(\frac{\rho_{0}}{\zeta}+\frac{\sigma_{y}}{\zeta^{i} \omega}\right)} \frac{\partial P}{\partial y}\right]-\frac{\zeta}{\rho_{0} c_{e}^{2}} \frac{\partial P^{2}}{\partial t^{2}}=0$

Assuming, the pressure perturbation $P$ to be harmonic in time,

$$
P(x, y, t)=p(x, y) e^{i \omega t}
$$

Eq. (23) becomes

$$
\begin{array}{r}
\frac{\partial}{\partial x}\left[\frac{1}{\left(\frac{\rho_{0}}{\zeta}-\frac{1 \sigma_{x}}{\zeta \omega}\right)} \frac{\partial p}{\partial x}\right]+\frac{\partial}{\partial y}\left[\frac{1}{\left.\left(\frac{\rho_{0}}{\zeta}-\frac{i \sigma_{y}}{\zeta \omega}\right)\right]}\right] \frac{\partial p}{\partial y} \\
+\frac{\zeta_{\omega}^{2}}{\rho_{0} c_{e}^{2}} p=0
\end{array}
$$

For simplicity, let

$$
\begin{aligned}
c_{x} & =\frac{\rho_{0}}{\zeta}-1 \frac{\sigma_{x}}{\zeta \omega} \\
\varepsilon_{y} & =\frac{\rho_{0}}{\zeta}-1 \frac{\sigma_{y}}{\zeta \omega} \\
\mu & =\frac{\zeta}{\rho_{0} c_{e}^{2}}
\end{aligned}
$$

Thus, the wave equation becomes

$$
\frac{\partial}{\partial_{x}}\left[\frac{1}{\varepsilon_{x}} \frac{\partial p}{\partial x}\right]+\frac{\partial}{\partial y}\left[\frac{1}{\varepsilon_{y}} \frac{\partial p}{\partial y}\right]+\mu \omega^{2} p=0
$$

Equation (28) represents the governing wave equation to be solved by finite element theory.

For later use in applying the finite element theory, it is convenient to express $\mathrm{Eq} .(28)$ in vector form.

$$
\nabla \cdot\{\bar{E} \cdot \nabla p\}+\mu \omega^{2} p=0
$$

where the property tensor $\bar{E}$ is represented by

$$
\bar{E}=\left(\begin{array}{cc}
\frac{1}{\varepsilon_{x}} & 0 \\
0 & \frac{1}{\varepsilon_{y}}
\end{array}\right)
$$

and the vector product of the tensor $\bar{E}$ and $a$ vector $\nabla p$ follows the common definition (Eq. A.4-19, Ref.6)

\section{Uniform Duct Analytical Solutions}

The analytical solutions of Eq. (28) for wave propagation in a uniform hard wall duct having an anechoic entrance and exit will be employed to give the termination boundary condition for the finite element region. The analytical solution for pressure waves traveling between parallel hard plates where the boundary condition is

$$
\frac{\partial P}{\partial y}=0 \text { at } y=0 \text { and } y=b_{a}
$$

is given as (see for example Ref. 7, p. 504)

$$
\begin{aligned}
p_{a}(x, y)= & \sum_{n=1}^{N_{m}} A_{n}^{+} \cos \left(\frac{(n-1) \pi}{b_{a}} y\right) e^{-1 k} x n^{x} \\
& +\sum_{n=1}^{N_{m}} A_{n}^{-} \cos \left(\frac{(n-1) \pi}{b_{a}} y\right) e^{+i k} \times n^{x}
\end{aligned}
$$

For the $e^{\text {twt }}$ time dependance used here, the $A_{n}^{+} e^{-1 k} \times n^{x}$ term represents a wave propagating in the positive $x$ direction while the $A_{n}^{-} e^{1 k} \times n^{x}$ represents a wave moving in the negative $x$ direction.

$$
\begin{aligned}
& \text { The axial wave number } k_{x n} \text { in Eq. (23) is } \\
& k_{x n}=k \sqrt{1-\left(\frac{(n-1) \pi}{b_{a} k}\right)^{2}} \quad \frac{(n-1) \pi}{b_{a} k} \leq 1 \\
& k_{x n}=-i k \mid \sqrt{\left(\frac{(n-1) \pi}{b_{a} k}\right)^{2}-1} \frac{(n-1) \pi}{b_{a} k}>1 \\
& k=\omega \sqrt{\mu \varepsilon}=\frac{\omega}{c}
\end{aligned}
$$

The modal expression represented by Eq. (32) has been truncated to a total of $N_{m}$ modes of the infinite number possible. Thus, a total of $\mathrm{N}_{m}$ unknown modal amplitudes $A T, A_{2}, \ldots$ ANm have been introduced. The $A^{+}$terms will be assumed as known. $N_{m}$ constraint equations will be required to determine each of these unknown reflection coefficients. The equations used to define these coefficients will be introduced in the following section on boundary conditions.

A similar solution exists at the exit, except only positive going waves are considered 


$$
p_{b}(x, y)=\sum_{n=1}^{N} B_{n}^{+} \cos \left(\frac{(n-1) \pi}{b_{b}} y\right) e^{-i k x n^{x}}
$$

where $k_{x n}$ in Eq. (36) is based on characteristic duct height of exit $b_{b}$.

\section{Boundary Conditions}

A variety of boundary conditions will be used in the finite element solution of Eq. (28) for the model problem which is displayed in schematic form in Fig. 4. Each of the required conditions will now be briefly discussed.

\section{Input Condition}

The analysis assumes a given number $\mathrm{N}_{\mathrm{m}}$ of propagating $A_{n}^{+}$modes (see Eq. (32)). These modes effectively set the level of the scalar pressure field in the finite element region and can be viewed as the equivalent Dirichlet boundary conditions required for elliptic boundary value problems as defined by Eq. (28).

\section{Pressure Continuity at Inlet and out let}

In general, the scalar pressure field is continuous across an interface except where sources are present. Thus, the boundary condition at the interface between the entrance duct and the finite element region requires

$$
p_{a}=\tilde{p}\left(x=0 ; 0<y<b_{a}\right)
$$

where $p_{a}$ is the modal representation of the scalar pressure field in the analytical inlet region given by Eq. (32) and $\tilde{p}$ represents the finite element approximation for pressure at the interface. The hat over $\tilde{p}$ implies an approximate finite element numerical solution to the true solution.

At the inlet interface, shown by the dashed line in Fig. 4, the scalar pressure $p_{a}$ in the analytical region given by Eq. (32) must match the pressure field defined by the finite element modal points along the boundary interface. A weighted residual approach was used herein with the weighting function equal to the eigen functions.

$$
\int_{0}^{b}\left[p_{a}(y)-\tilde{p}(y)\right] \cos \left(\frac{(m-1) \pi y}{b_{a}}\right) d y \quad x_{x=0}=0
$$

$$
\left(N_{m} \text { equations } m=1,2,3, \cdots-N_{m}\right)
$$

Equation (38) represents $N_{m}$ separate equations; one for each coefficient defined in Eq. (32). The symbol $m$ has been introduced for the mode number equation to make it distinct from the multiple $n$ mode number that make up the $P_{a}$ and $P_{b}$ analytical functions.

At the exit,

$$
\int_{0}^{b_{b}}\left[p_{b}(y)-\tilde{p}(y)\right] \cos \left(\frac{(m-1) \pi y}{b_{b}}\right) d y \quad x=L=0
$$

\section{Velocity Continuity}

In addition to pressure continuity, the axial acoustic velocity must also be continuous across the interface to the finite element region.

$$
u_{a}=\tilde{u} \quad\left(x=0 ; 0<y<b_{a}\right)
$$

Again, $u_{a}$ is the modal representation of the scalar axial velocity field in the analytical solution and $\tilde{u}$ represents the approximate finite element solution. Using the momentum equations

(Eq. (21)) to express the axial velocity in term of the pressure field yields

$$
\frac{1}{\rho_{\mathrm{a}}} \frac{\partial \mathrm{p}}{\partial \mathrm{a}}=\frac{1}{\varepsilon_{\mathrm{x}}} \frac{\partial \tilde{\mathrm{p}}}{\partial \mathrm{x}}
$$

where again an $e^{+1 \omega t}$ time dependance has been assumed. The weak form of the finite element solution will be employed in the solution of this problem. In this form, a contour integral term will be developed which will contain a natural boundary condition of the form $\nabla p \cdot n$ where $n$ represents the unit outward normal. Equation (41) can now be generalized to

$$
\nabla \tilde{p} \cdot \bar{n}=\frac{-\varepsilon x}{\rho_{a}} \frac{\partial p_{a}}{\partial x} \quad(\text { in let })
$$

and at the exit

$$
\nabla \tilde{p} \cdot \bar{n}=\frac{+\varepsilon x}{\rho_{b}} \frac{\partial p_{b}}{\partial x} \quad(e x i t)
$$

In general, the gradient of the pressure field is continuous except where there is a step change in density. The sign change in Eqs. (42) and (43) comes directly from the directional change of the unit outward normal.

\section{Hard Wall Boundary Condition}

At the hard walls shown in Fig. 4, the transverse acoustic velocity is zero. Again, using the momentum equations to relate the acoustic velocity to the pressure fields requires

$$
\begin{gathered}
\nabla p \cdot \bar{n}=0 \\
\text { FINITE ELEMENT THEORY }
\end{gathered}
$$

The finite element formulation of the inhomogeneous wave equation is now generated by using the weighted residual approach with the Galerkin approximation to obtain an integral form of the variable property wave equation over the whole (global) doma in.

The continuous domain $D$ is first divided into a number of discrete areas as shown in Fig. 2 . The particular pattern chosen has been found to give accurate results for a minimum number of elements. ${ }^{8}$

In the classical weighted residual manner, the pressure field is curve fitted in terms of all the unknown modal values $p_{\{}\left(x_{1}, y_{1}\right)$. The finite element aspects of converting Eq. (28) and the boundary conditions into an appropriate set of global difference equations can be found in text books (e.g., Ref. 9) as well as Ref. 10 and for conciseness wili not be presented herein. In Ref. 10, an exact finite element analog of Eq. (28) for electromagnatic propaga- 
tion has been solved by Galerkin finite element theory with linear elements.

\section{Experimental Apparatus and Procedure}

A test apparatus was constructed to verify the numerical theories for a tunnel having a fibrous absorbing wall and no mean flow. The general acoustic duct system described in Ref. 11 was modified into the simple no-flow apparatus as shown schematically in Fig. 3. The system was adapted to simulate plane wave propagation in an infinite duct. The following paragraphs describe the acoustic system including components and general operation.

\section{Source}

Sound was generated by a $120 \mathrm{~W}, 300 \mathrm{~Hz}$ to $6 \mathrm{kHz}$ driver. In the experiment reported herein, a random noise generator provided a signal to the amplifier which in turn powers the acoustic driver. The duct temperature was at $28^{\circ} \mathrm{C}$. Since the first nonplane mode begins propagating at a frequency of $1701 \mathrm{~Hz}$, the choice of $1560 \mathrm{~Hz}$ for the data frequency guarantees that only plane waves will propagate in the straight portion of the duct far from the fibrous absorption area.

\section{Test Section}

The sound travels through a 10 by $3.81 \mathrm{~cm} \mathrm{rec-}$ tangular test section. This $1.4 \mathrm{~m}$ long section consists of 16 flat detachable plates (eight on top and eight on bottom). The fibrous absorbing test piece, to be described shortly, was inserted in place of the bottom flat piece at location five. An exponential horn was also attached to the downstream end of the test section. For these experiments, the horn was fitted with an acoustic foam wedge to absorb the incident sound to approximate an anechoic termination. This anecholc termination simulates the infinitely long exit duct assumed in the analysis.

\section{Eibrous Test Plece}

The fiber test plece was constructed from epoxy and metal. A $4.6 \mathrm{~cm}$ deep by $14.36 \mathrm{~cm}$ long and $9.2 \mathrm{~cm}$ wide cavity was filled with Kevlar fibers with a overall density of $0.00792 \mathrm{~g} / \mathrm{cc}$, a mean fiber diameter of $0.61254 \mathrm{~mm}$ and with an effective porosity $\zeta$ of 0.9945 . A four mesh metal screen covered the face as well as compressing the Kelvar in the cavity.

\section{Microphone Installation}

Two $0.64 \mathrm{~cm}(1 / 4 \mathrm{in}$.$) diameter condenser micro-$ phones were used to determine the acoustic field. The microphone designated (A) was used to monitor the source strength of the signal, while microphone (B) was used to determine the pressure and phase angle along the flat surface above the fibrous absorption test piece. The output of each microphone was analyzed to determine the r.m.s. pressure at a test frequency of $1560 \mathrm{~Hz}$. The flat microphone test holder plate is shown in Fig. 4 along with the fibrous absorption piece mounted in the duct. Three microphone holder plates were mounted above the fibrous absorption test piece at locations 4,5 , and 6 shown in Fig. 3. This aluminum microphone plate was fabricated with $0.64 \mathrm{~cm}(1 / 4 \mathrm{in}$.) diameter holes which allowed one microphone (B) to be tra- versed in the axial direction in increments of $0.953 \mathrm{~cm}(3 / 8 \mathrm{in.})$. The microphone holder plates were fabricated with an insulator in each hole, so that the microphones were electrically insulated from the test plate. During a measurement, the microphone's membrane was positioned flux with the surface of the test plate (protective shields were removed).

The response of these microphones was flat to $25 \mathrm{kHz}$. a standard acoustic source was used to check the system amplification. The measured (normalized) r.m.s. acoustic pressures are shown in Table 1. The lengths are normalized to the duct height $(3.81 \mathrm{~cm})$ and the rms acoustic pressures are normalized by microphone (A). The fiberous material begins at $x / 3.81$ of 4.47 and ends at 8.167 .

\section{Discussion of Results}

For theory and code validation, the finite element solution is first applied to a case where an exact analytical solution exists. Next, the experimental results are compared to theoretical predictions.

\section{Reflection and Transmission With Normal Incidence}

The first case considers a step change in material density from a non-dimensional value of 1 to a value of 4 at an axial position of $x$ equal to 0.25 inside the finite element grid. In this case, the porosity is unity, and the viscous loss coefficients $\sigma_{x}$ and $\sigma_{y}$ are assumed to be zero so that $\varepsilon_{x}$ and $\varepsilon_{y}$ take on the real values of 1 and 4 , respectively. The $\mu$ parameter was assumed to be 1 and the dimensionless incident frequency was assumed to be $2 \pi$.

As shown in Fig. 5 , the finite element and exact analytical theories (Ref. 12, p. 83) are in excellent agreement for the rms pressure. The reflections from the interface between the two density changes are clearly represented by the standing wave pattern ahead of the interface. Observe that the magnitude of the pressure increases inside the material.

\section{Experimental Axial Pressure Profile - Hersh}

\section{Properties}

The normalized rms pressure from Table 1 are plotted against axial distance in Fig. 6 and compared to the finite element solution of Eq. (28). The material properties were evaluated using Hersh's correlation 4 with

$$
\begin{array}{ll}
P_{r}=0.71 & v^{\prime}=1.51 E-05 \mathrm{~m}^{2} / \mathrm{sec} \\
\gamma=1.4 & d^{\prime}=1.25410-5 \mathrm{~m} \\
V_{p}=1.0 & V_{n}=0.44 T_{n}=1.0
\end{array}
$$

and

$$
\zeta=0.9945
$$

and found to be

$$
\begin{aligned}
& \varepsilon_{x}=1.0055-10.0996 \\
& \varepsilon_{y}=1.0055-10.1131 \\
& \mu=1.0004-10.0479
\end{aligned}
$$

As seen in Fig. 6, the theory and experiment are in reasonable agreement. The magnitude of the 
entrance standing wave is in close agreement although a slight shift in the pattern is seen. The standing wave pattern determines the reflected wave. The fall off of pressure in the central portion of the duct is also handled reasonably well. However, the pressure rise at the exit is over estimated although the proper trend is predicted.

The slight standing wave pattern in the exit duct data is a resuit of reflections of $f$ the absorbing wedge in the test section horn. Since the theory assumes that there is no reflected energy at the exit, a downstream standing wave pattern cannot, of course, arise in analytical predictions. The absence of reflected energy at the duct exit in the theory may account for the shift in the predicted standing wave pattern at the entrance.

It can be shown that the standing wave pattern in a duct can be written as

$$
\frac{|p|^{2}}{|A|^{2}}=1+R_{f}^{2}+2 R_{f} \cos \left(2 k x+\theta_{f}\right)
$$

where $R_{f}$ is the magnitude of the termination reflection coefficient and $\theta_{f}$ is the reflection coefficient phase angle. The standing wave pattern has a minimum value when

$$
\cos \left(2 k x_{\min }+\theta_{f}\right)=-1
$$

or

$$
2 k x_{\min }=-(2 n-1) \pi-\theta_{f}
$$

which applies when the axial coordinate gets more positive toward the termination. A measurement of the termination reflection coeffictent at $1560 \mathrm{~Hz}$ shows that $\theta_{f}=-0.45 \pi$, which results in a shift of the minima towards more positive values by about 0.67 axial units. The data points agree with the direction of this shift but the measurements shown in Fig. 6 have about a 0.5 axial unit shift compared to the theory which is only a 0.17 axial unit difference. This difference is within the accuracy of the microphone measurements.

Experimental Axial Pressure Profiles - Modifted Hersh Properties

0ther observations suggest that Hersh's empirical coefficient o could be underestimating viscous effects. Using an impedance tube, Dahl and $\mathrm{Rice}^{2}$ reported larger measured absorption than predicted with the Hersh modal in the $1500 \mathrm{~Hz}$ frequency range. Consequently, to check the sensitivity of the predictions to the viscous loss coefficlent $\sigma$, the imaginary component of $\varepsilon$ has been increased to

$$
\varepsilon_{X}=\varepsilon_{y}=1.0055-10.21335
$$

As seen in Fig. 7, the theory and experiment are in better agreement at the exit. The present numerical theory may offer an attractive theoretical approach to evaluating viscous loss coefficients in bulk absorbers.

\section{Concluding Remarks}

The finite element model was developed to solve for the acoustic pressure field in a region that was nonhomogeneous. The derivations from the gov- erning equations assumed no mean flow and that the material properties could vary with position resulting in a nonhomogeneous variable property twodimensional wave equation. This eliminated the necessity of finding the boundary conditions between the different materials. Consequently, complex structure can be easily modeled simply by changing the property of elements in the calculational domain.

For a two media region consisting a part air and part bulk absorber, a model was used to describe the bulk absorber properties in two directions. An experiment to verify the numerical theory was conducted in a rectangular duct with no flow and with absorbing material mounted on one wall. Changes in the sound field, consisting of planar waves, was measured on the wall opposite the absorbing material. As a function of distance along the duct, fairly good agreement was found in the standing wave pattern upstream of the absorber and in the decay of pressure level opposite the absorber.

The numerical formulation is relatively simple to use and appears to give accurate modeling of experimental data. The theory may be a useful tool in the evaluation of viscous loss coefficients in bulk materials.

\section{References}

1. Woodward, R.P., "Measured Noise of a Scale Model High Speed Propeller at Simulated Takeoff/ Approach Conditions, "AIAA Paper 87-0526, Jan. 1987. (NASA TM-88920).

2. Baumeister, K.J. and Eversman, W., "Modeling the Effects of Wind Tunnel Wall Absorption on the Acoustic Radiation Characteristics of Propellers," AIAA Paper 86-1876, July 1986. (NASA TM-87333).

3. Dah1, M.D. and Rice, E.J., "Measured Acoustic Properties of Variable and Low Density Bulk Absorbers," ASME Paper 85-WA/NCA-6, Nov. 1985. (NASA TM-87065).

4. Hersh, A.S. and Walker, B., "Acoustic Behavior of Fibrous Bulk Materlals," AIAA Paper 80-0986, June 1980

5. Baumeister, K.J., Eversman, W., Astley, R.J., and White, J.W. "Acoustics in Variable Area Duct: Finite Element and Finite Difference Comparisons to Experiment," AIAA Journal, Vol. 21, No. 2, Feb. 1983, pp. 193-199.

6. Bird, R.B., Stewart, W.E., and Lightfoot, E.N., Transport Phenomena, John Wiley and Sons, New York, 1960.

7. Morse, P.M. and Ingard, K.U., Theoretical Acoustics, McGraw-Hi11, New York, 1968.

8. Baumeister, K.J., "Effect of Triangular Element Orientation on Finite Element Solutions of the He lmholtz Equation," ASME Paper 86-WA/NCA-11, Dec. 1986. (also NASA TM-87351).

9. Segerlind, L.J., Applied Finite Element Analysis, John Wiley and Sons, New York, 1976. 
10. Baumeister, K.J., "Finite Element Analysis of Electromagnetic Propagation in an Absorbing Wave Guide," NASA TM-88866, 1986.

11. Succ1, G.P., Baumeister, K.J., and Ingard, K.U., "Interaction of a Turbulent Jet Nolse Source With Transverse Modes in a Rectangular Duct," NASA TP-1248, 1978.
12. Temkins, S., Elements of Acoustics, John Wiley and Sons, 1981.

13. Skudrzyk, E.J., The Foundations of Acoustics, Springer-Verlag, New York, 1977, P. 305.

TABLE 1

\begin{tabular}{|c|c|c|c|c|c|}
\hline Position & $x / 3.81$ & $\underset{\text { rms }}{\mathrm{p}_{\mathrm{B}} / \mathrm{p}_{\mathrm{A}}}$, & Position & $x / 3.81$ & $\underset{\text { rms }}{\mathrm{p}_{\mathrm{B}} / \mathrm{p}_{\mathrm{A}}}$ \\
\hline $\begin{array}{r}1 \\
2 \\
3 \\
4 \\
5 \\
6 \\
7 \\
8 \\
9 \\
10 \\
11 \\
12 \\
13 \\
14 \\
15 \\
16 \\
17 \\
18 \\
19 \\
20 \\
21 \\
22 \\
23 \\
24\end{array}$ & $\begin{array}{l}0.00 \\
\\
.5 \\
.75 \\
1.00 \\
1.25 \\
1.5 \\
1.75 \\
2.00 \\
2.25 \\
2.50 \\
2.75 \\
3.00 \\
3.25 \\
3.50 \\
3.75 \\
4.417 \\
4.667 \\
4.917 \\
5.167 \\
5.417 \\
5.667 \\
5.917 \\
6.167\end{array}$ & $\begin{array}{l}1.0 \\
1.105 \\
1.078 \\
.9904 \\
.8655 \\
.7066 \\
.5791 \\
.5358 \\
.6013 \\
.7428 \\
.8871 \\
1.004 \\
1.077 \\
1.088 \\
1.049 \\
.7495 \\
.6395 \\
.5510 \\
.4882 \\
.4386 \\
.3900 \\
.3296 \\
.2599\end{array}$ & $\begin{array}{l}25 \\
26 \\
27 \\
28 \\
29 \\
30 \\
31 \\
32 \\
33 \\
34 \\
35 \\
36 \\
37 \\
38 \\
39 \\
40 \\
41 \\
42 \\
43 \\
44 \\
45 \\
46 \\
47 \\
48\end{array}$ & $\begin{array}{r}6.417 \\
6.667 \\
6.917 \\
7.167 \\
7.417 \\
7.667 \\
7.917 \\
8.167 \\
8.833 \\
9.083 \\
9.333 \\
9.583 \\
9.833 \\
10.083 \\
10.333 \\
10.583 \\
10.833 \\
11.083 \\
11.333 \\
11.583 \\
11.833 \\
12.083 \\
12.333 \\
12.583\end{array}$ & $\begin{array}{r}0.1793 \\
.0990 \\
.0723 \\
.1304 \\
.1983 \\
.2541 \\
.3009 \\
.3383 \\
.3944 \\
.3981 \\
.3929 \\
.3790 \\
.3582 \\
.3323 \\
.3141 \\
.3078 \\
.3155 \\
.3332 \\
.3563 \\
.3817 \\
.3934 \\
.3960 \\
.3894 \\
.3738\end{array}$ \\
\hline
\end{tabular}




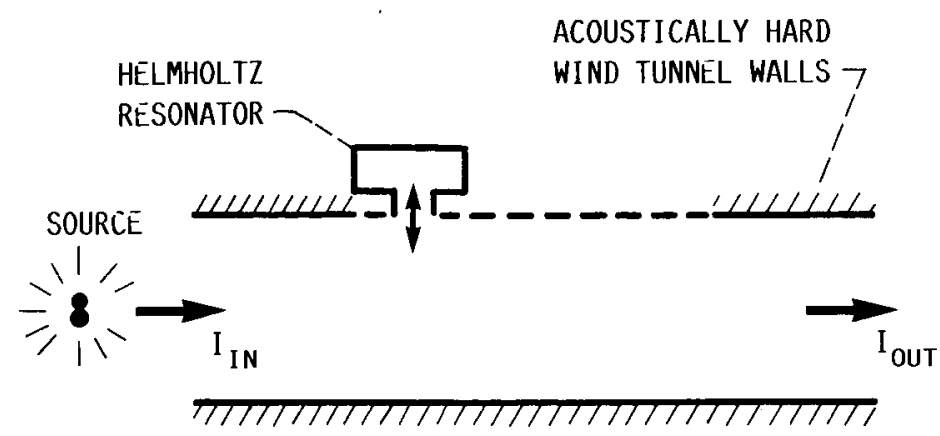

(A) LOCALLY REACTING ABSORBING ADMITTANCE BOUNDARY CONDITION.

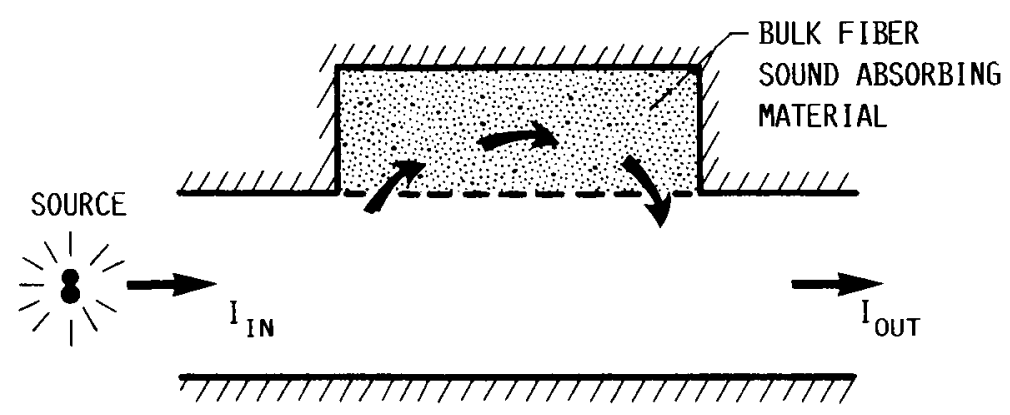

(B) EXTENDED REACTING INHOMOGENEOUS ABSORBING BOUNDARY.

FIGURE 1. - BOUNDARY CONDITIONS EMPLOYED TO SIMULATED SOFT WALL WIND TUNNEL.

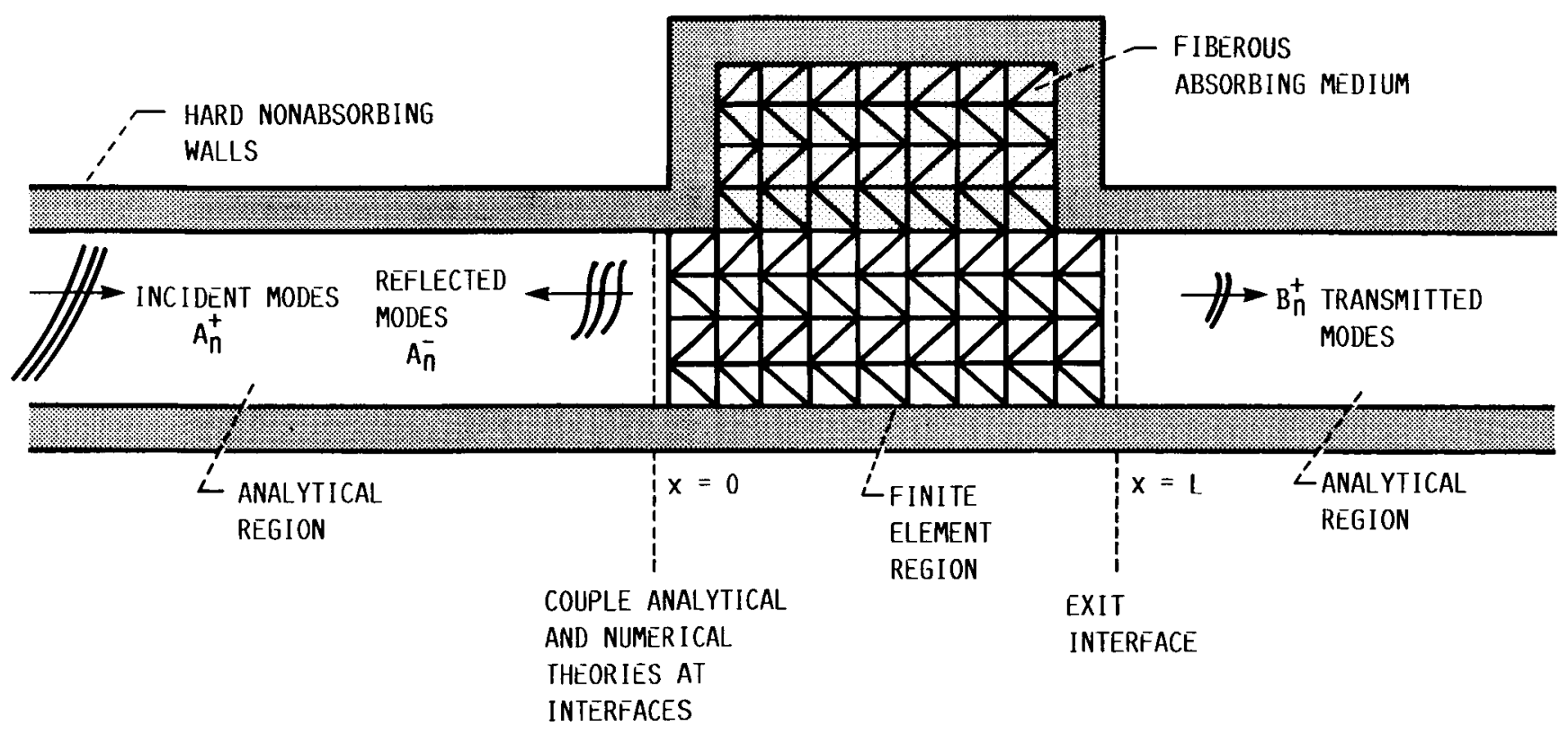

FIGURE 2. - TWO DIMENSIONAL DUCT FINITE ELEMENT MODEL. 


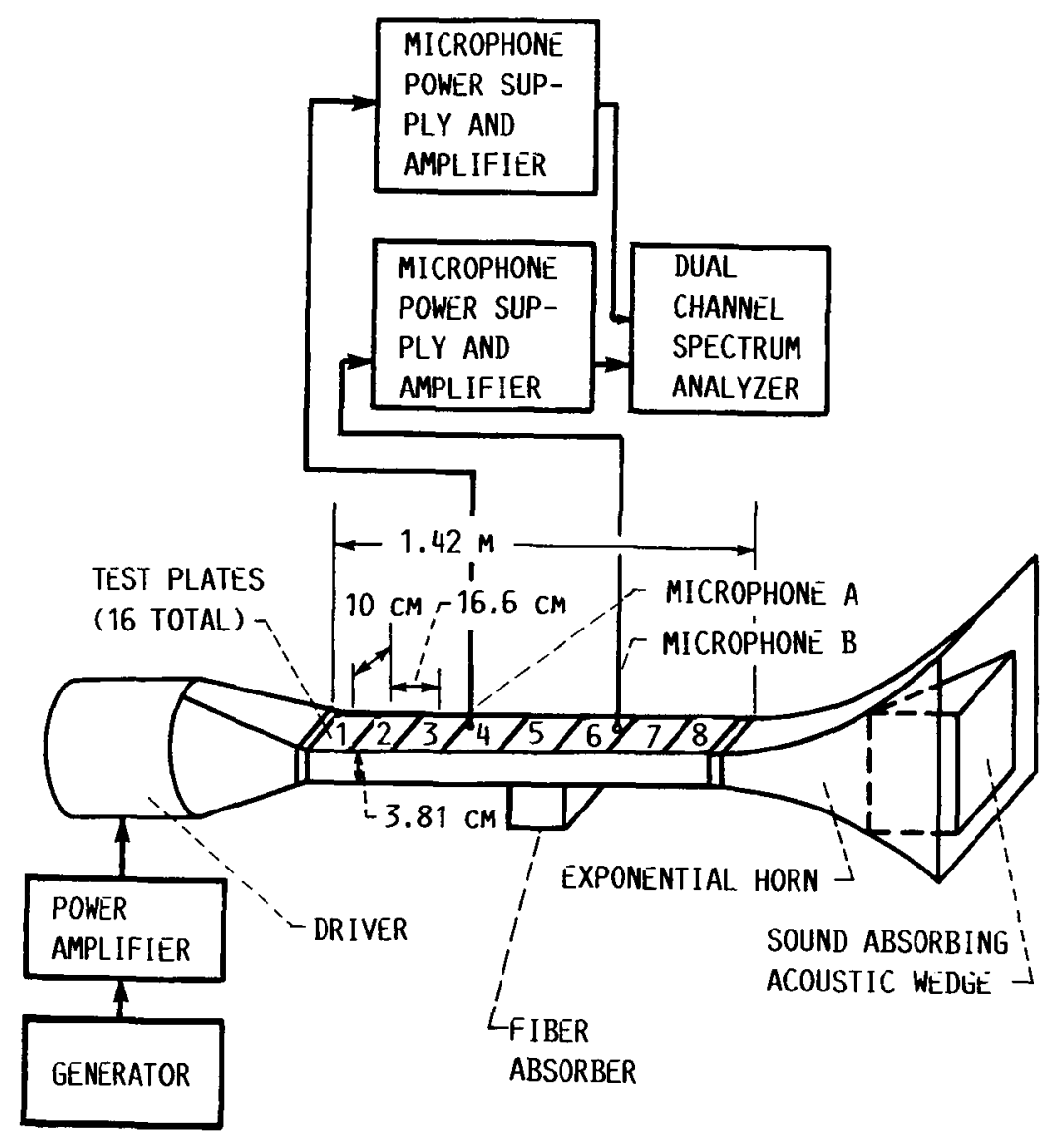

FIGURE 3. - NO-FLOW ACOUSTIC DUCT TEST SECTION AND INSTRUMENTATION. 
ORIGINAL PAGE IS
OF POOR OUALITY

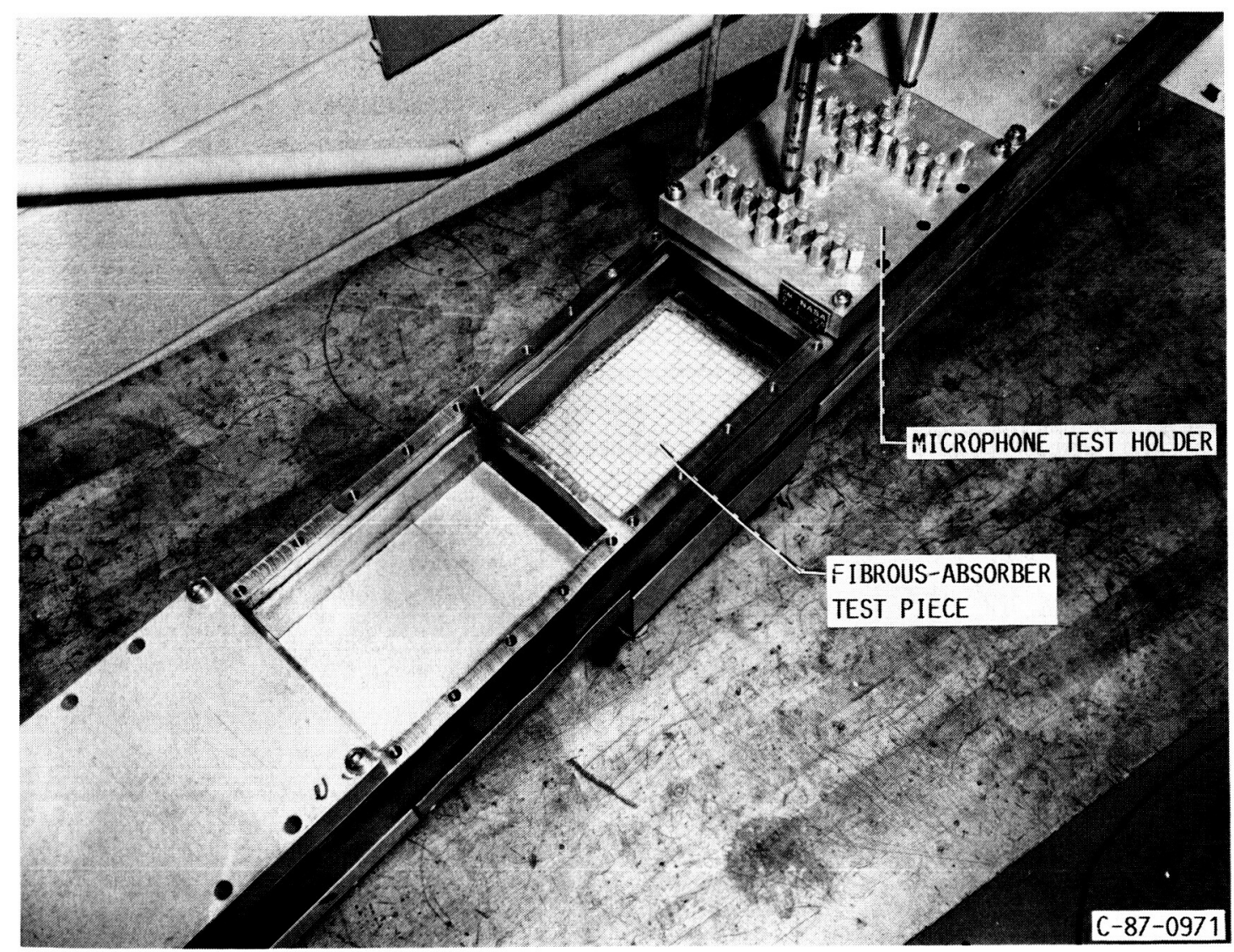

FIgURE 4. - MICROPHONE TEST PLATE AND MOUNTED FIBROUS ABSORBER. 


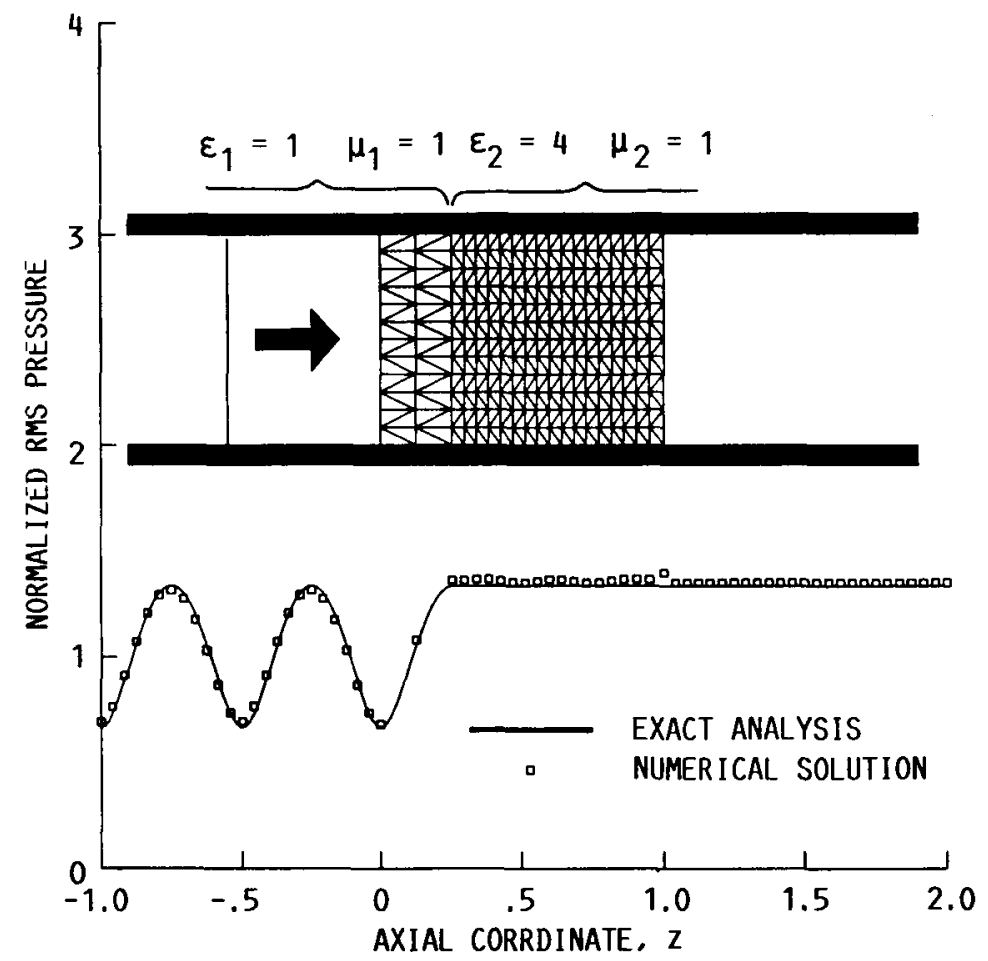

FIGURE 5. - A COMPARISON OF THE MAGNITUDE OF THE AXIAL RMS PRESSURE VARIATION ALONG THE LOWER WALL IN A UNIFORM DUCT WITH HARD WALLS AND A CHANGE IN PROPERTIES OF THE MEDIA AT $Z$ OF $0.25\left(\varepsilon_{1}=1.0\right.$ AND $\left.\varepsilon_{2}=4.0\right)$ AS OBTAINED BY USING AN EXACT SOLUTION AND A FINITE SOLUTION FOR A PLANE WAVE (MODE-ONE) INCIDENT AT $Z=0$ WITH $\omega=2 \pi$. 


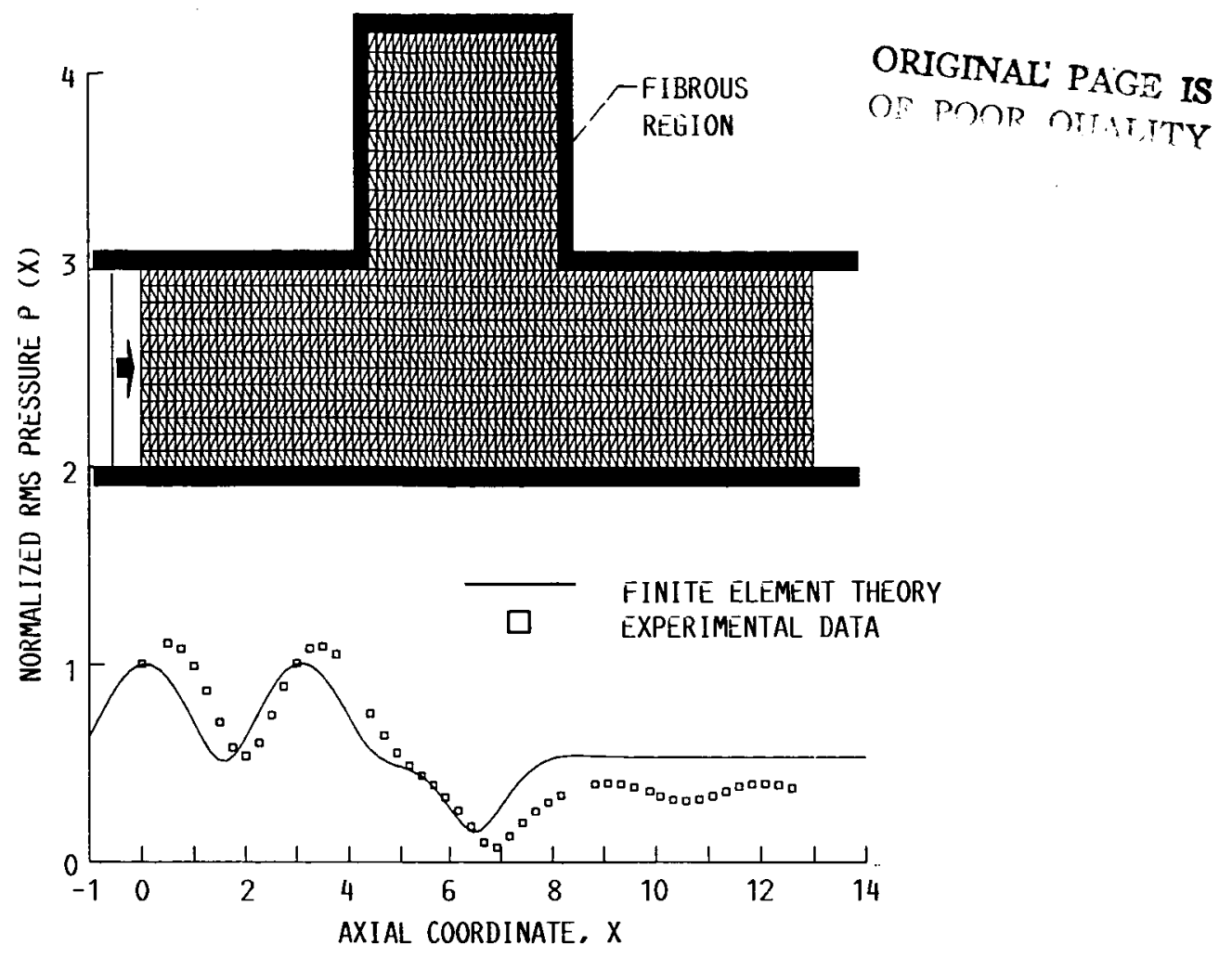

FIGURE 6. - EXPERIMENTAL AND THEORETICAL AXIAL PRESSURE PROFILE WITH PROPERTIES FROM HERSH'S MODEL $(\omega=1.047)$.

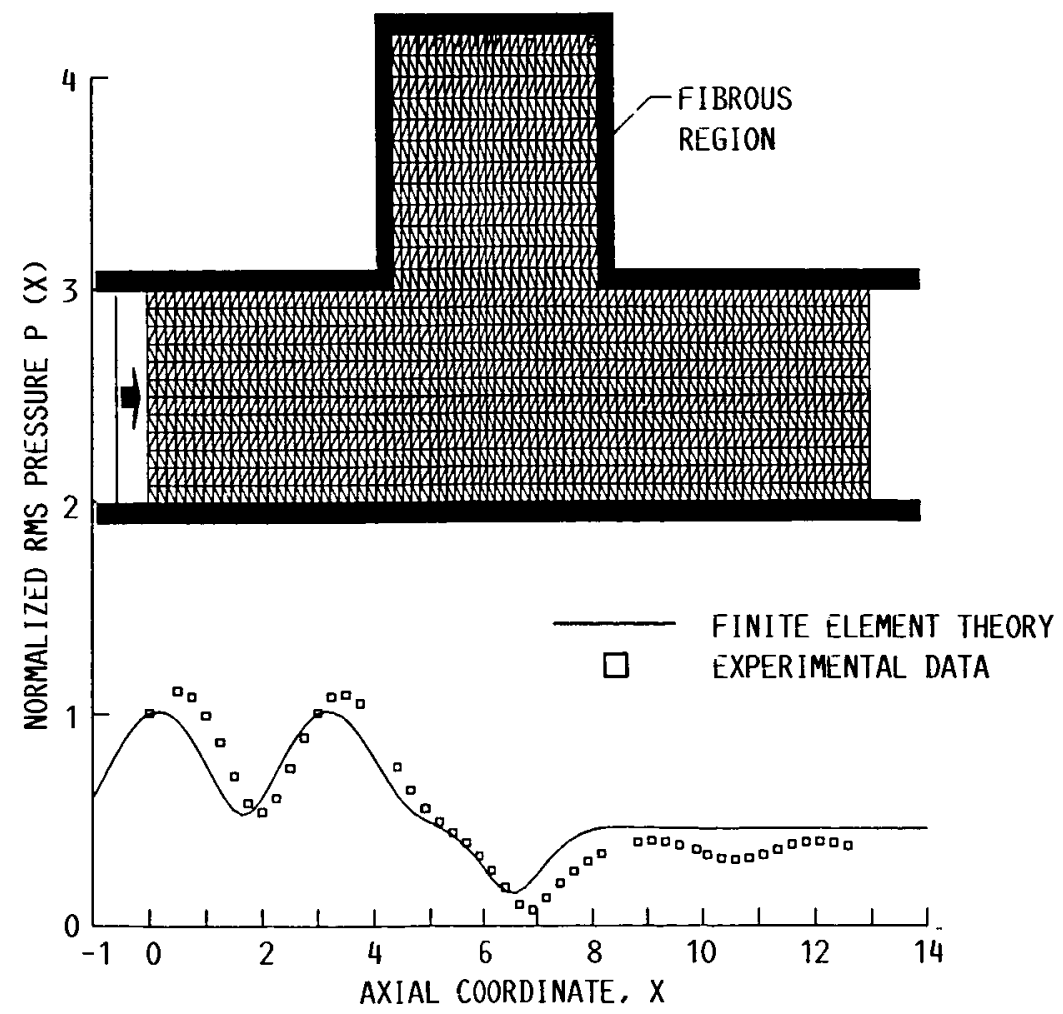

FIGURE 7. - EXPERIMENTAL AND THEORETICAL AXIAL PRESSURE PROFILE WITH PROPERTIES FROM MODIFIED HERSH'S MODEL $(\omega=1.047)$. 


\begin{tabular}{|c|c|c|c|}
\hline \multicolumn{4}{|c|}{ Report Documentation Page } \\
\hline $\begin{array}{l}\text { 1. Report No. } \\
\text { NASA TM-100149 }\end{array}$ & 2. Government Accession No. & \multicolumn{2}{|c|}{ 3. Recipient's Catalog No. } \\
\hline \multicolumn{2}{|c|}{$\begin{array}{l}\text { A Finite Element Model for Wave Propagation } \\
\text { in an Inhomogeneous Material Including } \\
\text { Experimental Validation }\end{array}$} & \multicolumn{2}{|c|}{$\begin{array}{l}\text { 6. Performing Organization Code } \\
505-62-21\end{array}$} \\
\hline \multirow{2}{*}{\multicolumn{2}{|c|}{$\begin{array}{l}\text { 7. Author(s) } \\
\text { Kenneth J. Baumeister and Milo D. Dahl }\end{array}$}} & \multicolumn{2}{|c|}{$\begin{array}{l}\text { 8. Performing Organization Report No. } \\
E-3471\end{array}$} \\
\hline & & \multicolumn{2}{|l|}{ 10. Work Unit No. } \\
\hline \multirow{2}{*}{\multicolumn{2}{|c|}{$\begin{array}{l}\text { 9. Performing Organization Name and Address } \\
\text { National Aeronautics and Space Administration } \\
\text { lewis Research Center } \\
\text { Cleveland, Ohio } 44135\end{array}$}} & \multicolumn{2}{|c|}{\begin{tabular}{|l} 
11. Contract or Grant No. \\
\end{tabular}} \\
\hline & & \multicolumn{2}{|c|}{$\begin{array}{l}\text { 13. Type of Report and Period Covered } \\
\text { Technical Memorandum }\end{array}$} \\
\hline \multicolumn{2}{|c|}{$\begin{array}{l}\text { 12. Sponsoring Agency Name and Address } \\
\text { National Aeronautics and Space Administration } \\
\text { Washington, D.C. } 20546\end{array}$} & \multicolumn{2}{|c|}{\begin{tabular}{|l} 
14. Sponsoring Agency Code \\
\end{tabular}} \\
\hline \multicolumn{4}{|c|}{$\begin{array}{l}\text { Prepared for the } 11 \text { th Aeroacoustics Conference sponsored by the American } \\
\text { Institute of Aeronautics and Astronautics, Sunnyvale, Californta, October 19-21, } \\
1987 \text {. }\end{array}$} \\
\hline \multicolumn{4}{|c|}{$\begin{array}{l}\text { 16. Abstract } \\
\text { A finite element model was developed to solve for the acoustic pressure field in } \\
\text { a nonhomogeneous region. The derivations from the governing equations assumed } \\
\text { that the material properties could vary with position resulting in a nonhomogene- } \\
\text { ous variable property two-dimensional wave equation. This eliminated the neces.- } \\
\text { sity of finding the boundary conditions between the different materials. For a } \\
\text { two media region consisting of part air (in the duct) and part bulk absorber (in } \\
\text { the wall), a model was used to describe the bulk absorber properties in two } \\
\text { directions. An experiment to verify the numerical theory was conducted in a } \\
\text { rectangular duct with no flow and absorbing material mounted on one wall. } \\
\text { Changes in the sound field, consisting of planar waves was measured on the wall } \\
\text { opposite the absorbing material. As a function of distance along the duct, } \\
\text { fairly good agreement was found in the standing wave pattern upstream of the } \\
\text { absorber and in the decay of pressure level opposite the absorber. }\end{array}$} \\
\hline $\begin{array}{l}\text { 17. Key Words (Suggested by Author(s)) } \\
\text { Finite element } \\
\text { Bulk absorbers } \\
\text { Acoustics } \\
\text { Kevlar }\end{array}$ & $\begin{array}{l}\text { 18. Dist } \\
\text { Unc } \\
\text { STA }\end{array}$ & $\begin{array}{l}\text { d - unitimite } \\
\text { ry } 70\end{array}$ & \\
\hline $\begin{array}{l}\text { 19. Security Classif. (of this report) } \\
\text { Unc las if ied }\end{array}$ & $\begin{array}{l}\text { Security Classif. (of this page) } \\
\text { Unc las s if ied }\end{array}$ & $\begin{array}{r}\text { 21. No of pages } \\
14\end{array}$ & $\begin{array}{r}\text { 22. Price* } \\
\mathrm{A02}\end{array}$ \\
\hline
\end{tabular}

NASA FORM 1626 OCT $86 \quad$ *For sale by the National Technical Information Service, Springfield, Virginia 22161 